\title{
WACC and a Generalized Tax Code
}

\author{
Sven Husmann, Lutz Kruschwitz and Andreas Löffler* \\ version from 10/06/2001 \\ ISSN 0949-9962
}

\begin{abstract}
We extend the WACC approach to a tax system having a firm income tax and a personal income tax of the investor as well. We use an artifical tax system incorporating most of the $\mathrm{G}-7$ national tax codes as for example the classical or the imputation systems.

On our website (www.wacc.de) WACC formulas according to many of the actual G-7 national tax codes can be found.
\end{abstract}

\section{Introduction}

Any firm valuation method needs to take taxes into account. If in particular interest payments are tax-deductible, the value of an unlevered firm will differ by the so-called tax shield from the value of a levered cash flow stream. One of the most compelling valuation methods is the weighted average cost of capital (WACC) approach. In this approach, the tax advantages from debt are evaluated by adapting the risk premium in the valuation formula.

The first WACC formula was given by Modigliani \& Miller (1963). Their idea was based upon a constant expectation of future cash flows as well as a "constant interest bill". In this case the leverage ratio is a random variable. Miles \& Ezzell (1980) have pointed out that with constant leverage ratios this approach will not yield the correct value of the firm. For the case of a perpetual rent they provided a different WACC

\footnotetext{
${ }^{*}$ Husmann and Kruschwitz are from the Lehrstuhl für Bank- und Finanzwirtschaft, Freie Universität Berlin, Boltzmannstr. 20, D-14195 Berlin; Löffler is from the Lehrstuhl für Banken und Finanzierung,Universität Hannover, Königsworther Platz 1, D-30167 Hannover. Corresponding author is Andreas Löffler (AL@wacc.de).

We thank Jörg Laitenberger for pointing out an error in an earlier version of our paper.
} 
formula. Notice that the WACC formula given in Miles \& Ezzell (1980) might yield arbitrage if an additional assumption (perpetual rent, see assumption 1 below) is not satisfied. Nevertheless, their result for infinite lifetime remains true: for more details see Löffler (2001).

Although this WACC approach can be found in almost every paper on valuation, surprisingly less is known if the tax systems differs from the one assumed in Modigliani \& Miller (1963), who concentrated on the American tax code with its corporate income tax and used simplifying assumptions about personal income taxes. In a classical or even an imputation system the personal income tax does not create a tax shield if interest and dividends are taxed at the same rate. But even if interest and dividends are taxed differently this is no longer true. Furthermore, since the income tax alters the return of the unlevered firm the weighted average cost of capital changes. Therefore, valuing a company without taking the income tax into account will give wrong results.

Miller (1977) investigated a model with personal and corporate income taxes but focused on equilibrium considerations. His two-period model had the so-called classical system where the corporate tax cannot be deducted from the personal tax. DeAngelo \& Masulis (1980) extended Miller's model and generalized the tax code to include such non-debt corporate tax shields as depreciation deductions and investment credits. Since both papers consider a two-period model their results are not directly comparable to our approach.

In a recent paper Coopers \& Nyborg (1999) analyze a similar generalization of the WACC approach. Their tax system however does not distinguish between EBIT and cash flows, hence the tax base of the firm income tax they use is not appropriate. Furthermore, the claim that their result can easily be generalized to multiperiod projects is wrong since the example of an arbitrage strategy using the Miles-Ezzell-WACC formula in Löffler (2001) shows that the WACC approach even with a firm income tax alone must be handled with care.

Our aim is to apply the WACC approach to a more generalized tax system that can incorporate most of existing G-7 national tax codes and that in particular will take personal taxes into account. Hence, we will formulate a model that has the tax codes from Japan, USA as well as most European Countries as special cases. We will give a WACC formula for this generalized tax code. The paper is organized as follows: the next chapter introduces the model. In particular we show that the US and most of the European tax codes can be implemented in our system. We then develop WACC formulas for finitely and infinitely living firms.

\section{The Model}

There are $T$ periods of time $t=0,1, \ldots, T$. The future $t>0$ is uncertain, time horizon is the intervall $[0, T]$. With time $t$ information evolves about the true state of the world.

Diskussionspapier 243 (2001), FB Wiwi, Universität Hannover 
This can be formalized using a probability space and a filtration $\mathcal{F}_{t}$ (for details see Duffie (1988, p. 130)). The investor forms expectations using her probability measure and values a firm with lifetime $T$. The unlevered company has cash flows before tax $\widetilde{C} F_{t}$. Earnings before interest and taxes are denoted by $\widetilde{E B I T} T_{t}$. Cost of capital (expected returns) of the unlevered firm remain constant through time and will be denoted by $r^{U}$. Face value of equity ("capital paid in") of the unlevered and levered firm will be denoted by $\widetilde{E}_{t}^{U}$ and $\widetilde{E}_{t}$.

The levered firm raises risk-free debt $\widetilde{D}_{t}$ (bonds) at time $t$. In the case of finite lifetime the managers of the firm agree to retire the loan completely by the end of the planning period $\widetilde{D}_{T}=0$. The creditor evidently faces no default risk although there is no fixed timetable for the retirements. Interest payments $\widetilde{Z}_{t}$ derive from the loan $\widetilde{D}_{t}$ at the beginning of the period.

If the investors retire loan at time $t$ the equity of the firm would change. Since we want to relate the value of the levered firm to the value of the unlevered firm we need to assume that investments (and therefore cash flows), EBITs and retained earnings are the same for both companies. This implies

$$
\widetilde{E}_{t}^{U}=\widetilde{E}_{t}+\widetilde{D}_{t}
$$

To get general valuation formulas it will not be appropriate to focus on a particular national tax system, e.g. the USA or the German tax code. Therefore, we consider an artificial tax law that will include both corporate and personal income taxes. We avoid here the various different tax bases due to the national tax codes or rulings concerning accounting principles. We focus on the fact that in some countries the firm tax is partially or fully - deductible from the personal tax while other countries have a classical tax system. Also tariffs differ heavily from country to country.

To build a model of a generalized tax code we now claim that the sum of firm and personal taxes related to the company's cash flow can be represented by the model used in Miles \& Ezzell (1985) and Löffler (2001)

$$
\widetilde{T}_{t}=\widetilde{T}_{t}^{U}\left(\widetilde{C} F_{t}-\widetilde{E}_{t-1}^{U}+\widetilde{E}_{t}^{U}, \widetilde{E B} I T_{t}\right)-\tau \widetilde{Z}_{t}, \quad t \geq 1,
$$

where the tax payments of the unlevered firm $\widetilde{T}_{t}^{U}\left(\widetilde{C} F_{t}-\widetilde{E}_{t-1}^{U}+\widetilde{E}_{t}^{U}, \widetilde{E B} I T_{t}\right)$ is a linear function depending on free cash flows (minus changes in capital paid in) as well as firm and personal tax rates and their interaction. $\tau$ (a number that may well be negative or even zero) represents the net tax saving per dollar of interest paid.

If an investor abstains from buying shares, she can invest in the capital market. Investment in stocks in the capital market will be taxed at $\tau_{S}$, the discount rate of the unlevered firm after personal income tax is $r^{U}$. We furthermore assume that the riskless discount rate after personal income tax is $r_{f}$.

We will now show that this formulation is indeed able to cope with many of the tax systems we find in Europe, Japan and the USA. In particular we will consider the

Diskussionspapier 243 (2001), FB Wiwi, Universität Hannover 
classical system, an imputation system and the German tax code since this code does not fit into the first two systems. See the website www.wacc.de for descriptions of some of the actual national tax codes and the corresponding WACC formulas.

\subsection{The classical system}

We start with the classical system that today can be found in the USA and in Belgium, Denmark, the Netherlands, Sweden, and Switzerland. Typically the earnings of the company are taxed at both the company's and the shareholders' level. Let $\tau_{F}$ be the firm tax rate. Then the firm tax amounts to

$$
\widetilde{T}_{F, t}=\tau_{F}\left(\widetilde{E B} I T_{t}-\widetilde{Z}_{t}\right) .
$$

The payout to the shareholders mounts up to $\widetilde{C} F_{t}-\left(\widetilde{D}_{t-1}+\widetilde{Z}_{t}-\widetilde{D}_{t}\right)-\widetilde{T}_{F, t}$. The creditors receive $\widetilde{D}_{t-1}+\widetilde{Z}_{t}-\widetilde{D}_{t}$. Furthermore, the stock holders receive a tax relief for lowering equity ("capital paid in") by $\widetilde{E}_{t-1}-\widetilde{E}_{t}$. We assume that dividends are subject to the personal income tax $\tau_{S}$ whereas interest is taxed at $\tau_{B}$. If we bear in mind that both shareholders and creditors have different sources of income (dividends and interest) their personal taxes run to

$$
\widetilde{T}_{P, t}=\tau_{S}\left(\widetilde{C} F_{t}-\left(\widetilde{D}_{t-1}+\widetilde{Z}_{t}-\widetilde{D}_{t}\right)-\left(\widetilde{E}_{t-1}-\widetilde{E}_{t}\right)-\widetilde{T}_{F, t}\right)+\tau_{B} \widetilde{Z}_{t}
$$

Notice, that the personal income tax depends on the difference $\widetilde{E}_{t}-\widetilde{E}_{t-1}-\left(\widetilde{D}_{t-1}-\widetilde{D}_{t}\right)$ which by (1) is the same for the unlevered company. Putting both taxes together and rearranging terms yields equation (2) with

$$
\begin{aligned}
\widetilde{T}_{t}^{U} & =\tau_{S}\left(\widetilde{C} F_{t}-\widetilde{E}_{t-1}^{U}+\widetilde{E}_{t}^{U}\right)+\tau_{F}\left(1-\tau_{S}\right) \widetilde{E B} I T_{t}, \\
\tau & =-\tau_{B}+\tau_{S}+\tau_{F}\left(1-\tau_{S}\right) .
\end{aligned}
$$

If in a classical system dividends and interest are taxed at the same rate and if there would be no firm income tax there is no tax shield since in this case $\tau=0$. If only a firm income tax $\tau$ is taken into account we arrive at the model of Miles \& Ezzell (1980) who analyzed the US tax code.

\subsection{Imputation systems}

If the firm tax adds to the tax base of the personal income tax and is then completely deducted from the tax paid, we speak of an imputation system. Thus firm taxes may be seen as mere prepayments on personal taxes. An imputation type of tax regime is now employed in Italy and France. Given this system the sum of the personal taxes amounts to

$$
\widetilde{T}_{P, t}=\tau_{S}\left(\widetilde{C} F_{t}-\left(\widetilde{D}_{t-1}+\widetilde{Z}_{t}-\widetilde{D}_{t}\right)-\left(\widetilde{E}_{t-1}-\widetilde{E}_{t}\right)-\widetilde{T}_{F, t}+\widetilde{T}_{F, t}\right)+\tau_{B} \widetilde{Z}_{t}-\widetilde{T}_{F, t} .
$$

Diskussionspapier 243 (2001), FB Wiwi, Universität Hannover 
Notice, that the personal income tax depends on the difference $\widetilde{E}_{t}-\widetilde{E}_{t-1}-\left(\widetilde{D}_{t-1}-\right.$ $\widetilde{D}_{t}$ ) which by (1) is the same for the unlevered company. By adding the firm tax we get equation (2) with (again we use $\tau_{B}$ as tax rate for interest and $\tau_{S}$ as tax rate for dividends)

$$
\widetilde{T}_{t}^{U}=\tau_{S}\left(\widetilde{C} F_{t}-\widetilde{E}_{t-1}^{U}+\widetilde{E}_{t}^{U}\right), \quad \tau=-\tau_{B}+\tau_{S} .
$$

In a partial imputation system a part of received dividend adds to the tax base and a certain amount of the dividend is granted as tax relief from the personal income tax. This type of tax regime can be found in the United Kingdom and Canada. Let $\gamma_{1}>0$ be that amount of received dividend that adds to the tax base of the personal income tax and let $\gamma_{2}>0$ be the percentage the personal income tax is lowered. Then the sum of the personal taxes amounts to

$$
\widetilde{T}_{P, t}=\left(\tau_{S} \gamma_{1}-\gamma_{2}\right)\left(\widetilde{C} F_{t}-\left(\widetilde{D}_{t-1}+\widetilde{Z}_{t}-\widetilde{D}_{t}\right)-\left(\widetilde{E}_{t-1}-\widetilde{E}_{t}\right)-\widetilde{T}_{F, t}\right)+\tau_{B} \widetilde{Z}_{t}
$$

Notice, that the personal income tax depends on the difference $\widetilde{E}_{t}-\widetilde{E}_{t-1}-\widetilde{D}_{t-1}-\widetilde{D}_{t}$ which by (1) is the same for the unlevered company. Adding the firm tax and some simple rearrangement yields equation (2) with

$$
\begin{aligned}
\widetilde{T}_{t}^{U} & =\left(\tau_{S} \gamma_{1}-\gamma_{2}\right)\left(\widetilde{C} F_{t}-\widetilde{E}_{t-1}^{U}+\widetilde{E}_{t}^{U}\right)+\left(1+\gamma_{2}-\gamma_{1} \tau_{S}\right) \tau_{F} \widetilde{E B I} T_{t}, \\
\tau & =1-\tau_{B}-\left(1-\tau_{F}\right)\left(1+\gamma_{2}-\gamma_{1} \tau_{S}\right) .
\end{aligned}
$$

\subsection{The German tax code}

A more complicated tax regime is the current German Tax Code. It has two firm income taxes (a "Gewerbesteuer" similar to a franchise tax, and a "Körperschaftsteuer" which is a corporate income tax ). Interest payments on the firm's debt allow for the tax base only by 50 percent. Hence, the franchise tax can be written as

$$
\widetilde{T}_{g, t}=\tau_{g}\left(\widetilde{E B} I T_{t}-\frac{1}{2} \widetilde{Z}_{t}\right)
$$

whereas the firm income tax reads

$$
\widetilde{T}_{k, t}=\tau_{k}\left(\widetilde{E B I} T_{t}-\widetilde{Z}_{t}-\widetilde{T}_{g, t}\right) .
$$

Adding both taxes gives an artificial firm income tax of

$$
\widetilde{T}_{F, t}=\left(\tau_{g}+\tau_{k}\left(1-\tau_{g}\right)\right) \widetilde{E B} I T_{t}-\left(\frac{\tau_{g}}{2}+\tau_{k}\left(1-\frac{\tau_{g}}{2}\right)\right) \widetilde{Z}_{t} .
$$

The full imputation system was dropped and replaced by a different system in 2000 . Interest is taxed at $\tau_{e}$, where dividends for compensation are taxed by only 50 percent

Diskussionspapier 243 (2001), FB Wiwi, Universität Hannover 
of $\tau_{e}$ ("Halbeinkünfteverfahren", a similar system can be found in Austria). Hence, the investor's personal tax equation reads

$$
\widetilde{T}_{P, t}=\frac{\tau_{e}}{2}\left(\widetilde{C}_{t}-\left(\widetilde{D}_{t-1}+\widetilde{Z}_{t}-\widetilde{D}_{t}\right)-\left(\widetilde{E}_{t-1}-\widetilde{E}_{t}\right)-\widetilde{T}_{F, t}\right) .
$$

Notice, that the personal income tax depends on the difference $\widetilde{E}_{t}-\widetilde{E}_{t-1}-\left(\widetilde{D}_{t-1}-\widetilde{D}_{t}\right)$ which by (1) is the same for the unlevered company. The creditor's personal tax equation reads

$$
\widetilde{T}_{P, t}=\tau_{e} \widetilde{Z}_{t} .
$$

Adding and inserting the firm taxes yields equation (2) with

$$
\begin{aligned}
\widetilde{T}_{t}^{U} & =\frac{\tau_{e}}{2}\left(\widetilde{C} F_{t}-\widetilde{E}_{t-1}^{U}+\widetilde{E}_{t}^{U}\right)+\left(1-\frac{\tau_{e}}{2}\right)\left(\tau_{g}+\tau_{k}\left(1-\tau_{g}\right)\right) \widetilde{E B I T} T_{t} \\
\tau & =-\frac{\tau_{e}}{2}+\left(1-\frac{\tau_{e}}{2}\right)\left(\frac{\tau_{g}}{2}+\tau_{k}\left(1-\frac{\tau_{g}}{2}\right)\right) .
\end{aligned}
$$

This tax system can be compared to the classical system where $\frac{\tau_{e}}{2}$ would be the personal tax on dividends and $\tau_{e}$ the personal tax on interest income. The firm income tax would be represented by a combination of the Gewerbe- and Körperschaftsteuer. Nevertheless, the combination in $\widetilde{T}_{t}^{U}$ is different from the corresponding term in $\tau$. A tax shield exists even if we ignore both firm income taxes since still $\tau \neq 0$.

\section{The WACC formula}

The classical WACC formula can only be derived if we assume that the cash flows after tax satisfy a condition similar to a stochastic differential equation used in time continuous theory (see the example of an arbitrage strategy using the Miles-Ezzell formula in Löffler (2001)). We have to assume that the cash flows of the firm, EBIT and equity (after being adjusted by a growth rate) form a martingale under the subjective probability measure.

Assumption 1 (growth assumption) The cash flows satisfy

$$
E\left[\widetilde{C} F_{t+1}-\widetilde{C} F_{t} \mid \mathcal{F}_{t}\right]=g_{t} \cdot \widetilde{C} F_{t}
$$

where $g_{t}$ is a deterministic growth rate. Furthermore, $\widetilde{E B I T}$

$$
E\left[\widetilde{E B} I T_{t+1} \mid \mathcal{F}_{t}\right]=\left(1+g_{t}\right) \widetilde{E B} I T_{t} .
$$

and the equity of the firm ("capital paid in") grow at the same rate

$$
E\left[\widetilde{E}_{t+1}^{U} \mid \mathcal{F}_{t}\right]=\left(1+g_{t}\right) \widetilde{E}_{t}^{U} .
$$

Diskussionspapier 243 (2001), FB Wiwi, Universität Hannover 
Let $l_{t}$ be the (deterministic) leverage ratio of the levered firm at time $t$, i.e. the quotient of the market value of debt and the market value of the levered firm. Now the following holds.

Proposition 1 (WACC formula) If assumption 1 is satisfied and the cost of capital are constant the value of the levered company satisfies

$$
V_{0}^{L}=\sum_{t=1}^{T} \frac{E\left[\widetilde{C} F_{t}-\tilde{T}_{t}^{U}\right]}{\left(\left(1-\frac{\tau r_{f}}{1+r_{f}} l_{t-1}\right)\left(1+r^{U}\right)\right)^{t}} .
$$

Proof. We prove that the tax payments of the unlevered firm form a martingal after adjusted by $g_{t}$. Since by (2) $\widetilde{T}_{t}^{U}$ is a linear function of the two arguments we have for any real numbers $a, b$

$$
\begin{aligned}
\mathrm{E}[ & {\left[\widetilde{T}_{t+1}^{U}\left(\widetilde{C} F_{t+1}-\widetilde{E}_{t}^{U}+\widetilde{E}_{t+1}^{U}, \widetilde{E B} I T_{t+1}\right) \mid \mathcal{F}_{t}\right] } \\
& =\mathrm{E}\left[a \cdot\left(\widetilde{C} F_{t+1}-\widetilde{E}_{t}^{U}+\widetilde{E}_{t+1}^{U}\right)+b \cdot \widetilde{E B I T} T_{t+1} \mid \mathcal{F}_{t}\right] \\
& =a \cdot \mathrm{E}\left[\widetilde{C} F_{t+1}-\widetilde{E}_{t}^{U}+\widetilde{E}_{t+1}^{U} \mid \mathcal{F}_{t}\right]+b \cdot \mathrm{E}\left[\widetilde{E B} I T_{t+1} \mid \mathcal{F}_{t}\right] \\
& =a \cdot\left(1+g_{t}\right)\left(\widetilde{C} F_{t}-\widetilde{E}_{t-1}^{U}+\widetilde{E}_{t}^{U}\right)+b(1+g) \cdot \widetilde{E B} I T_{t} \\
& =\left(1+g_{t}\right) \widetilde{T}_{t}^{U}\left(\widetilde{C} F_{t}-\widetilde{E}_{t-1}^{U}+\widetilde{E}_{t}^{U}, \widetilde{E B} I T_{t}\right) .
\end{aligned}
$$

Our models coincides with the one on Löffler (2001) if the firm income tax is $\tau$, the cost of capital of the unlevered firm are $r^{U}$, the riskless interest rate is $r_{f}$ and the cash flows after tax of the unlevered firm are $\widetilde{C} F_{t}-\widetilde{T}_{t}^{U}$. For a proof of the WACC formula see Löffler (2001).

The more interesting application is a formula for a firm having infinite lifetime.

Proposition 2 (infinite lifetime) If assumption 1 is satisfied for $g_{t}=g$ and leverage ratios and cost of capital are constant, the value of the levered company satisfies

$$
V_{0}^{L}=\frac{V_{0}^{U}}{1-\frac{r_{f}}{r^{U}-g} \frac{1+r^{U}}{1+r_{f}} \tau l} .
$$

Proof. Applying the formula for a geometric sum and using the expressions for $V_{0}^{U}$ gives the desired result.

\section{Conclusion}

We extended the WACC approach to a tax system having a firm income tax and a personal income tax of the investor as well. We use an artifical tax system incorporating most of the G-7 national tax codes: we have shown that our model can be modified to cover the classical or the (partial) imputation system and even the complicated German tax code.

Diskussionspapier 243 (2001), FB Wiwi, Universität Hannover 


\section{References}

Coopers, I. \& Nyborg, K. (1999), Discount rates and tax, IFA Working paper 285.

DeAngelo, H. \& Masulis, R. (1980), 'Optimal capital structure under corporate and personal taxation', Journal of Financial Economics 8, 3-29.

Duffie, D. (1988), Security Markets, Academic Press, Inc., San Diego.

Löffler, A. (2001), Miles-Ezzell's WACC approaches yields arbitrage. available on http://www.ssrn.com.

Miles, J. \& Ezzell, J. (1980), 'The weighted average cost of capital, perfect capital markets, and project life: A clarification', Journal of Financial and Quantitative Analysis 15, 719-730.

Miles, J. \& Ezzell, J. (1985), 'Reformulating tax shield valutation: A note', Journal of Finance 40, 1485-1492.

Miller, M. H. (1977), 'Debt and taxes', Journal of Finance 32, 261-275.

Modigliani, F. \& Miller, M. (1963), 'Corporate income taxes and cost of capital: A correction', American Economic Review 53, 433-443.

Diskussionspapier 243 (2001), FB Wiwi, Universität Hannover 